\title{
ALTERNATIVE FUELS AND CHEMICALS FROM SYNTHESIS GAS
}

\author{
FINAL
}

\section{Quarterly Status Report No. 13}

For the Period 1 October - 31 December 1997

\author{
Contractor \\ AIR PRODUCTS AND CHEMICALS, INC. \\ 7201 Hamilton Boulevard \\ Allentown, PA 18195-1501 \\ Prepared for the United States Department of Energy \\ Under Contract No. DE-FC22-95PC93052 \\ Contract Period 29 December 1994 - 28 December 1997
}

NOTE: AIR PRODUCTS DOES NOT CONSIDER ANYTHING IN THIS REPORT TO BE CONFIDENTIAL OR PATENTABLE. 


\section{DISCLAIMER}

This work was prepared as an account of work sponsored by the United States Government. Neither the United States nor the United States Department of Energy, nor any of their employees, makes any warranty, express or implied, or assumes any legal liability for the accuracy, completeness, or usefulness of any information, apparatus, product, or process disclosed, or represents that its use would not infringe privately owned rights. Reference herein to any specific commercial product, process, or service by trade name, mark, manufacturer, or otherwise, does not necessarily constitute or imply its endorsement, recommendation, or favoring by the United States Government or any agency thereof. The views and opinions of authors expressed herein do not necessarily state or reflect those of the United States Government or any agency thereof. 


\title{
Alternative Fuels and Chemicals from Synthesis Gas
}

\author{
Quarterly Technical Progress Report
}

1 October - 31 December 1997

\section{Contract Objectives}

The overall objectives of this program are to investigate potential technologies for the conversion of synthesis gas to oxygenated and hydrocarbon fuels and industrial chemicals, and to demonstrate the most promising technologies at DOE's LaPorte, Texas, Slurry Phase Alternative Fuels Development Unit (AFDU). The program will involve a continuation of the work performed under the Alternative Fuels from Coal-Derived Synthesis Gas Program and will draw upon information and technologies generated in parallel current and future DOE-funded contracts.

\section{RESULTS AND DISCUSSION}

\section{TASK 1: ENGINEERING AND MODIFICATIONS}

\subsection{Liquid Phase Fischer-Tropsch Demonstration}

A meeting was held with Shell International personnel in October to review filtration test results from experiments conducted at Shell laboratories and discuss modifications, run plan and schedule for the Fischer-Tropsch (F-T) IV run at LaPorte. Successful filtration was achieved at laboratory scale. Flux rate at twice the design rate was obtained at low membrane and longitudinal differential pressures. As a result, the F-T IV modifications were kicked off. The modification will include new filter elements, new element bundle arrangement, rebuilding the slurry pump and individualizing the filtration control. Shell will specify and purchase the new equipment. Improvements instituted by Air Products include purchase of significant hardware and software for the control system to fix a data acquisition glitch and upgrade the system, and purchase of a cooling-water pump to boost the cooling-water pressure. The run plan, which is similar to the FT III plan, calls for a 20-day run on syngas, including four process conditions, a baseline checkback, a tracer study at two conditions and a day on dynamic gas disengagement. A space-time yield of 150 will be the goal throughout the run. A start-up date of March 16 (catalyst loading) is targetted.

Work began on the F-T IV modifications in November. Shell's specification of filtration control valves was reviewed and approved by Process Engineering. The Machinery department finalized the pump modifications, and an order was placed with Sundstrand. A delivery date of 29 January was obtained. Shell ordered the filter elements and control valves, with delivery expected in the second half of January. These delivery dates are consistent with the start-up schedule. Flowsheet Change Notices were generated in December, and a hazard review is planned in January. 


\subsection{Liquid Phase DME Demonstration}

A meeting was held with PDO Environmental to discuss air emission permit requirements for the DME operations planned in the second half of 1998. The original 1991 permit covers the DME operations in the old reactor only, while the exemptions obtained in 1994 for the new reactor are valid solely for methanol and isobutanol operations. As a result, we would at least need an exemption from the Texas Natural Resources Control Council to conduct DME synthesis in the new reactor. Work has begun to generate material balances and conduct air permit exemption calculations to determine if we can qualify for an exemption.

\section{TASK 2: AFDU SHAKEDOWN, OPERATIONS, DEACTIVATION AND} DISPOSAL - No progress to report this quarter.

\section{TASK 3: RESEARCH AND DEVELOPMENT}

\subsection{Improved Processes for DME}

\subsubsection{Additive to Improve DME Catalyst Activity}

- A stable LPDMETM catalyst was obtained by adding a third material to the slurry oil. The dehydration catalyst used in this run, an aluminum phosphate sample, had caused accelerated deactivation of the methanol catalyst in the LPDME ${ }^{\mathrm{TM}}$ experiments without this component.

- This stabilization effect was confirmed for a second dual-catalyst system containing $\gamma$-alumina in another LPDME run. The methanol catalyst aged at the $\mathrm{LPMEOH}^{\mathrm{TM}}$ baseline rate.

- Further work is needed to understand the effect of the additive, since two other runs, using aluminum phosphate and $\gamma$-alumina, respectively, exhibited poor catalyst stability. The parameters that may cause this inconsistency are being investigated.

\subsubsection{Investigation of the Dependence of the Methanol Catalyst Deactivation Rate on Operating Conditions}

- Experiments continued to show the dependence of the deactivation rate of the methanol catalyst in the aluminum phosphate-containing dual catalyst system on the operating conditions. Four more sets of conditions were investigated. These data, along with the previous ones, will be used to understand the correlation between deactivation and operating conditions.

- The results from $\mathrm{XRD}$ and elemental analysis show neither $\mathrm{Cu} / \mathrm{ZnO}$ sintering nor poisoning are likely causes of the accelerated aging at the unfavorable operating conditions.

\subsubsection{Scaleup of Aluminum Phosphate for Summer 1998 LaPorte LPDME $^{\text {TM }}$ Trial}

- Air Products' laboratory procedure for preparation of our aluminum phosphate LPDME ${ }^{\mathrm{TM}}$ catalyst was reproduced successfully on the 30-gallon scale by our scaleup partner. When we tested their sample under our standard conditions, both the activity and stability of the LPDME ${ }^{\mathrm{TM}}$ reaction were similar to previous lab runs. Our partner has now begun 
working towards improving the manufacturability of the catalyst by debottlenecking the process and replacing certain lab procedures with more workable commercial equivalents.

- Samples were prepared both by Air Products and our partner using commercial-grade reagents. The performance of these materials in our standard LPDMETM experiment showed that the presence of contaminants in these raw materials does not seriously undermine their performance. However, we are concerned that the methanol catalyst deactivated at 0.07 $0.08 \%$ per hour - faster than our target of $0.05 \%$ per hour -- in two of the three experiments we have performed. Because the aluminum phosphates prepared from commercial-grade raw materials contain roughly 200 ppm iron (compared with roughly $50 \mathrm{ppm}$ in the aluminum phosphates from reagent-grade raw materials), we will scrutinize future runs to see if this trend persists. If so, we may have to work with our partner to identify alternative sources of aluminum and/or phosphoric acid.

- A lab preparation of aluminum phosphate in which the precipitation step was carried out at a constant $\mathrm{pH}$ of 9 produced a catalyst with very poor activity and catalytic stability. Our objective in this experiment was to determine whether constant $\mathrm{pH}$ precipitation would stabilize the catalyst activity by producing a more homogeneous material. A secondary objective was to see if constant $\mathrm{pH}$ precipitation would produce a less gelatinous product, which would be easier to wash and filter. In fact, we did find that the filtration time was substantially shorter for the sample precipitated at constant $\mathrm{pH}$.

\subsubsection{Understanding Liquid Phase Processes}

- The (Alternative Fuels Field Test Unit (AFFTU) was sent back to Kingsport to perform a parallel LPMEOH ${ }^{\mathrm{TM}}$ run which began simultaneously with the restart of the Demonstration Plant. The AFFTU reactor was run using feed syngas obtained directly from the feed pipe to the Demonstration Plant's reactor. Data obtained through the end of December showed that the catalyst in the AFFTU reactor was deactivating at roughly the typical laboratory baseline rate of $0.05 \%$ per hour. This reinforced the observation that the plant catalyst was not re-experiencing the comparatively rapid activity decline seen in the April-November run.

- Air Products also used the AFFTU to monitor the concentrations of key catalyst poisons in both the fresh syngas feed to the plant and the actual reactor feed. The actual reactor feed differs from the fresh syngas feed in that it is downstream of the activated carbon guard bed and also contains the recycled unreacted syngas. We saw very low levels of iron carbonyl $(<3$ $\mathrm{ppb}$ ) in the fresh feed and none in the reactor feed. We did not see any nickel carbonyl. Carbonyl sulfide levels were typically less than $10 \mathrm{ppb}$, although we did observe a significant COS excursion when Eastman switched gasifiers. During the two days after this gasifier changeover, the COS climbed as high as $300 \mathrm{ppb}$ in the fresh feed and approached $40 \mathrm{ppb}$ in the feed to the reactor. Since that time, COS concentrations have been $15-60 \mathrm{ppb}$ in the fresh feed and 2-10 ppb in the reactor feed. Our experience is that these levels of iron, nickel and sulfur, which have been measured in the actual reactor feed to this point, would not be expected to have any measurable impact on catalyst activity. 
- Samples of the catalyst slurry were withdrawn on days 1,4 and 10 of operation, and will be taken weekly thereafter. These will be analyzed to quantify the accumulation of various elements -- particularly iron, nickel, sulfur and arsenic -- on the catalyst. BET surface area, particle size distribution and copper crystallite size distribution (by XRD) will also be measured to provide a broader picture of the physical state of the catalyst. The feed stream to the Kingsport reactor was also sampled to determine the concentration of arsine.

Air Products performed a run in the lab in which five percent (by weight) of deactivated catalyst from the Kingsport reactor was added to a fully active LPMEOH ${ }^{\mathrm{TM}}$ slurry. The presence of this deactivated catalyst did not have any discernible effect on the activity or stability of the rest of the catalyst in the slurry. From this we conclude that small amounts residual slurry remaining in the reactor after shutdowns will not adversely impact the performance of fresh catalyst charged to the reactor.

\subsubsection{Miscellaneous}

- A topical report for DOE entitled "Catalyst Activity Maintenance for the Liquid Phase Synthesis Gas-to-Dimethyl Ether Process - Part I: An Investigation of the Cause and Mechanism of Catalyst Deactivation" was finished. This report covers Air Products' LPDME $^{\text {TM }}$ lab work from early 1994 to later 1995, prior to the onset of our aluminum phosphate work.

- A paper entitled "A Novel Mechanism of Catalyst Deactivation in Liquid Phase, Synthesis Gas to DME" was presented at the $7^{\text {th }}$ International Symposium on Catalyst Deactivation.

- A paper entitled "Development of a Process for Isobutylene from Isobutanol" was presented at the AIChE Meeting.

\section{Task 3.2 New Fuels from Dimethyl Ether (DME)}

\subsubsection{Overall 1QF98 Objectives}

The following set of objectives appeared in Task 3.2 of the previous Quarterly Technical Progress Report No. 12:

- Continue to define synthetic methodology to economically manufacture cetane enhancers.

- Document in a topical report the syngas to VAM routes.

\subsubsection{Background}

The overall objective for this project is to define a commercial process from synthesis gas to vinyl acetate (VAM) using dimethyl ether (DME) as a chemical building block. The three chemical step process is:

$$
\text { syngas } \rightarrow \text { dimethyl ether (DME) }
$$




$$
\begin{aligned}
& 2 \mathrm{DME}+4 \mathrm{CO}+\mathrm{H}_{2} \rightarrow \text { ethylidene diacetate }(\mathrm{EDA})+\text { acetic acid }(\mathrm{HOAc}) \\
& \mathrm{EDA} \rightarrow \text { vinyl acetate }(\mathrm{VAM})+\mathrm{HOAc}
\end{aligned}
$$

The overall economics of the proposed process are to be compared with the existing VAM process based on ethylene and acetic acid.

\subsubsection{Chemistry and Catalyst Development}

\section{(i) Studies on the Robustness of the Heterogeneous Catalyst}

The heterogeneous catalyst that anchors the active catalyst $\left[\mathrm{Rh}(\mathrm{CO})_{2} \mathrm{ICl}\right]{ }^{\Theta}$ for the hydrocarbonylation of DME to EDA and HOAc or the hydrogenation of acetic anhydride to EDA and HOAc is being tested for attrition, Rh loss and polymer modification through hydrogenation.

Experimentally an autoclave is charged with the heterogeneous catalyst, and the reactants are added through a high-pressure Isco pump. The system is pressurized with syngas, and after it is held at reaction temperature for 30 minutes, the autoclave is cooled and the liquid content is removed without opening the autoclave. New reactants are added to the heterogeneous catalyst remaining behind in the autoclave. The reaction sequence is repeated. At the end of the recycle experiment sequence (15-20 individual runs on the same initial charge of heterogeneous catalyst), the catalyst is removed for Rh analysis. Each solution is analyzed by GC for product, and then the solutions are grouped into batches of three or seven for concentration and finally analyzed for any soluble Rh.

\section{1a. Study 7: $190^{\circ} \mathrm{C}, 750 \mathrm{psi}, 5 / 95: \mathrm{H}_{2} / \mathrm{CO}$ Mixture - Carbonylation of Methyl Acetate to Acetic Anhydride $\left(\mathrm{Ac}_{2} \mathrm{O}\right)$}

The heterogeneous support (Reillex 425) was extracted with acetic acid for seven days before it was used to anchor the active catalyst. A plot of molarity (M) of $\mathrm{Ac}_{2} \mathrm{O}$ concentration is $1.8 \mathrm{M}$ from the first catalyst recycle until the 16th recycle. The Rh leaching rate has a fairly constant value of $0.7 \mathrm{mg}$ per hr over the 16 recycles of the catalyst.

\section{1b. Study 8: $180^{\circ} \mathrm{C}, 1500 \mathrm{psi}, 80 / 20: \mathrm{H}_{2} / \mathrm{CO}$ Mixture - Hydrogenation of Acetic Anhydride to EDA and HOAC}

The heterogeneous support (Reillex 425) was extracted with acetic acid for seven days before it was used to anchor the active catalyst. A plot of molarity (M) of EDA versus recycle number shows that the EDA concentration starts at $\sim 0.8 \mathrm{M}$ and falls off to $\sim 0.7 \mathrm{M}$ after 16 recycles. Approximately $50 \%$ of the rhodium is removed from the catalyst. The $\mathrm{Rh}$ leaching rate levels off to $0.8 \mathrm{mg}$ per hr over the 16 recycles.

\section{1c. Study 7-8 Summary}

The leaching rate for $\mathrm{Rh}$ from the organic polymer is similar to the results obtained in Studies 4 and 6 reported in Quarterly Technical Progress Report No. 12. There does not appear to be a leachable component within the polymer framework to account for the steady Rh leaching. Therefore, the leaching of $\mathrm{Rh}$ is a result of the chemistry. 


\section{1d. Recovery of Rh}

Recovery of $\mathrm{Rh}$ from process streams is a natural extension of expertise in handling polyvinylpyridine resins (Reillex) and the use of these materials to anchor a Rh catalyst through ionic attachment. The recovery of homogeneous $\mathrm{Rh}$ from carbonylation processes is expensive, and the capital cost of catalyst recovery section accounts for $\sim 40 \%$ of the total capital costs.

\section{(ii) Ethylidene Diacetate (EDA) to Vinyl Acetate}

The third chemical step in the overall syngas to vinyl acetate process is shown below:

$$
\mathrm{EDA} \rightarrow \mathrm{VAM}+\mathrm{HOAc}
$$

This reaction is actually an equilibrium with retro-reaction of EDA to acetic anhydride and acetaldehyde $(\mathrm{AcH})$.

$$
\mathrm{Ac}_{2} \mathrm{O}+\mathrm{AcH} \rightleftharpoons \mathrm{EDA} \rightleftharpoons \mathrm{VAM}+\mathrm{HOAc}
$$

Therefore, the conversion of EDA to VAM requires the cracking to be conducted with an excess of $\mathrm{Ac}_{2} \mathrm{O}$ to suppress the EDA retro-reaction to $\mathrm{Ac}_{2} \mathrm{O}$ and $\mathrm{AcH}$.

The object of a control experiment was to understand the "extra" acetic acid produced from the cracking of EDA. For every VAM produced, one acetic acid should also be formed. Therefore, a 1-gram sample of Amberlyst 15 (dry) was loaded with a 20-gram sample of EDA and distilled as described previously. Distillation time was approx. 0.3 hour. Components were determined via gas chromatography using amyl acetate as an internal standard. Carbon and oxygen balances approached $100 \%$. The table below shows the initial and final compositions for this distillation. We already know that the absence of $\mathrm{Ac}_{2} \mathrm{O}$ will allow the retro-reaction to proceed to a significant extent.

$$
\begin{aligned}
& \text { Initial EDA fed }=137 \text { mmole } \\
& \text { Composition of distillate: }
\end{aligned}
$$

$\begin{array}{ll}\mathrm{EDA} & =37 \text { mmole } \\ \mathrm{Ac}_{2} \mathrm{O} & =60 \text { mmole } \\ \mathrm{VAM} & =13 \text { mmole } \\ \mathrm{AcH} & =70 \text { mmole } \\ \mathrm{AcOH} & =72 \text { mmole }\end{array}$

As can be seen from the data above, 100 mmole of EDA were consumed; 60 mmole of $\mathrm{Ac}_{2} \mathrm{O}$ were formed, and the corresponding $\mathrm{AcH}$ was present to a first approximation. This indicates that 40 mmoles of VAM and 40 mmoles of AcOH should have been formed. Instead, 27 mmoles of VAM appear to be missing and approximately the same amount of excess AcOH produced. This suggests that VAM under these conditions is converted to AcOH by some undefined mechanism. Alternatively, VAM could be lost due to volatility, but this is less likely. 


\section{(iii) Cetane Blending Components}

The concept of adding an oxygenated compound or a blend of oxygenated compounds to diesel fuel in order to enhance the cetane value of the fuel is being investigated. Based on external testing by SwRI, a family of ethers has been identified as cetane enhancers. The blend of oxygenated compounds is potentially accessible from the oxidative coupling of dimethyl ether (DME).

One of the fixed-bed reactor units (atmospheric pressure) has been modified, and a Design Hazards Review (DHR) has been completed. The remaining fixed-bed reactor unit (800 psi pressure) will be available during the 2QFY98 after a DHR. In addition, a class $C$ hazards assessment has been completed on a thermogravimetric analysis (TGA) unit to be used for quick screening to gauge the reactivity of potential catalysts in the absence of $\mathrm{O}_{2}$. It is anticipated that a catalyst weight loss could signal the following chemistry:

$$
\mathrm{MO}+2 \mathrm{CH}_{3} \mathrm{OCH}_{3} \rightarrow \mathrm{CH}_{3} \mathrm{OCH}_{2} \mathrm{CH}_{2} \mathrm{OCH}_{3}+\mathrm{H}_{2} \mathrm{O}+\mathrm{M}
$$

Thermodynamic calculations have shown that the reaction of DME and $\mathrm{O}_{2}$ to yield 1,2dimethoxyethane and water is extremely favorable, with an equilibrium constant of $2 \times 10^{35}$ at $25^{\circ} \mathrm{C}$. Other DME oxidation reactions are also very favorable, and the challenge of finding a catalyst selective for oxidative coupling remains.

Air Products' Project Engineering department has been asked to calculate the cost (feedstock and capital) of the three-component composition from the oxidative coupling of DME based on a hypothetical process flow sheet.

\subsubsection{QFY98 Objectives}

Future plans for Task 3.2 will focus on the following areas:

- Continue to define synthetic methodology to economically manufacture cetane enhancers.

- Document in a topical report the syngas to VAM routes.

\subsection{New Processes for Alcohols and Oxygenates}

\subsubsection{Development of a Catalyst for Isobutanol Synthesis from Syngas (Institute for Technical Chemistry and Petrol Chemistry, RWTH Aachen, Germany)}

\section{Introduction}

In our search for a catalyst for isobutanol synthesis from syngas that is practicable for industrial applications, we have emphasized catalyst variation. Currently under investigation is the promotion of the $\mathrm{ZrO}_{2} / \mathrm{ZnO} / \mathrm{MnO} / \mathrm{K}_{2} \mathrm{O}$ catalyst system with various hydrogenation metals.

\section{Catalyst Preparation}

The $\mathrm{ZrO}_{2} / \mathrm{ZnO} / \mathrm{MnO} / \mathrm{K}_{2} \mathrm{O}$ catalyst was impregnated with rhodium, ruthenium, palladium and platinum acetylacetonate. As previously explained, these metals are expected to enhance 
formation of linear alcohols, even at the lower reaction conditions investigated here. This again is expected to enhance isobutanol formation.

Details of the preparation method are provided in Table 3.3.1.

Table 3.3.1

Preparation of the Tested Catalysts

\begin{tabular}{|l|l|}
\hline Composition & $\mathrm{ZrO}_{2} / \mathrm{ZnO} / \mathrm{MnO}$ \\
\hline Synthesis method & $\begin{array}{l}\text { coprecipitation }(\text { at } 353 \mathrm{~K} \text { and } \mathrm{pH} 9) \text { of the } \\
\text { nitrates }(1: 1: 1) \text { with } \mathrm{KOH}\end{array}$ \\
Impregnation method & $\begin{array}{l}\text { Incipient wetness } \\
\text { Static impregnation }(\mathrm{Pd} 1 \mathrm{static})\end{array}$ \\
Promoter load & $0.024(\mathrm{M} \mathrm{I})-0.10(\mathrm{M} \mathrm{II}) \mathrm{mmol} / \mathrm{g}_{\mathrm{cat}}$ \\
Calcination & $6 \mathrm{hr}$ at $723 \mathrm{~K}(1 \mathrm{~K} / \mathrm{min})$ \\
Reduction & $12 \mathrm{hr}$ at $548 \mathrm{~K}(1 \mathrm{~K} / \mathrm{min})$ with $5 \% \mathrm{H}_{2}$ in $\mathrm{N}_{2}$ \\
\hline
\end{tabular}

\section{Catalyst Screening}

The catalyst screening was executed in Unit II, which has been described in previous reports. The heating rate used in the experiments was $1{ }^{\circ} \mathrm{C} / \mathrm{min}$. After a stabilization period of $18 \mathrm{hr}$ at the reaction temperature, a product sample was taken over $90 \mathrm{~min}$. All experiments were executed at a pressure of $12.5 \mathrm{MPa}$, a GHSV of $11,600 \mathrm{hr}^{-1}$ and reaction temperatures of 623 and $658 \mathrm{~K}$. The results obtained over the impregnated catalysts were compared to those obtained over the unimpregnated $\mathrm{ZrO}_{2} / \mathrm{ZnO} / \mathrm{MnO} / \mathrm{K}_{2} \mathrm{O}$-catalyst (Tables 3.3.2 and 3.3.3).

At $623 \mathrm{~K}$ the $\mathrm{ZrO}_{2} / \mathrm{ZnO} / \mathrm{MnO} / \mathrm{K}_{2} \mathrm{O}$ catalyst showed only minor activity towards isobutanol, the main product being methanol (Table 3.3.2). Impregnation with the metals did increase activity towards linear alcohols. Unfortunately, this did not increase isobutanol formation.

At the higher reaction temperature, promotion of the $\mathrm{ZrO}_{2} / \mathrm{ZnO} / \mathrm{MnO} / \mathrm{K}_{2} \mathrm{O}$ catalyst led to an increase in linear alcohol formation compared with the unimpregnated catalyst (Table 3.3.3). None of the promoted $\mathrm{ZrO}_{2} / \mathrm{ZnO} / \mathrm{MnO} / \mathrm{K}_{2} \mathrm{O}$ catalysts gave a higher yield of isobutanol than the unimpregnated catalyst. For the platinum, palladium and ruthenium catalysts, a higher load led to even higher yields of ethanol and propanol.

To check the influence of the impregnation method, the $0.024 \mathrm{mmol} / \mathrm{g}_{\text {cat }}$ palladium catalyst was also synthesized following the static impregnation method used in prior investigations. The static impregnated catalyst showed a catalytic behavior comparable to the incipient wetness catalyst.

\section{Conclusions}

Promotion with various hydrogenation metals, rhodium, platinum and palladium, did not lead to an increase in isobutanol yield. As reported previously, only the $\mathrm{ZrO}_{2} / \mathrm{ZnO} / \mathrm{MnO} / \mathrm{K}_{2} \mathrm{O}$ catalyst with a $0.024 \mathrm{mmol} / \mathrm{g}_{\text {cat }}$ copper load showed improved isobutanol yield. 
This first series of experiments in improving the activity of the $\mathrm{ZrO}_{2} / \mathrm{ZnO} / \mathrm{MnO} / \mathrm{K}_{2} \mathrm{O}$ catalyst at moderate reaction conditions will be continued by more closely examining the influence of copper. Additionally, tests with higher loads and combinations of different metals are planned.

Table 3.3.2

Product Distribution and STY Over Different $\mathrm{ZrO}_{2} / \mathrm{ZnO} / \mathrm{MnO} / \mathrm{K}_{2} \mathrm{O}-$ Catalysts; Unit II, $\mathrm{p}=12.5 \mathrm{MPa}, \mathrm{GHSV}=11,600 \mathrm{hr}^{-1}, \mathrm{~V}_{\text {cat }}=3.0 \mathrm{ml}, \mathrm{D}_{\text {cat }}=0.25-0.50 \mathrm{~mm}$, Syngas $1: 1$ $623^{\circ} \mathrm{K}$

\begin{tabular}{|c|c|c|c|c|c|}
\hline Promoter $\mathbf{M}^{\mathrm{a}}$ & - & $\mathbf{R h} \mathbf{I}$ & Rh II & Pt I & Pt II \\
\hline \multicolumn{6}{|l|}{$\begin{array}{l}\text { Liquid product } \\
\text { distribution }\end{array}$} \\
\hline$\%$ methanol & 86 & 92 & 90 & 83 & 94 \\
\hline$\%$ ethanol & $<1$ & 1 & 1 & 1 & 1 \\
\hline$\%$ n-propanol & $<1$ & 1 & 1 & $<1$ & $<1$ \\
\hline$\%$ i-butanol & 3 & 1 & 2 & 1 & 1 \\
\hline$\%$ 2-methylbutanol-1 & $<1$ & $<1$ & $<1$ & $<1$ & $<1$ \\
\hline \multicolumn{6}{|l|}{ STY $\left[g /\left(\mathbf{l}_{\text {cat }} \cdot h\right)\right]$} \\
\hline methane & $<10$ & $<10$ & $<10$ & $<10$ & 12 \\
\hline methanol & 420 & 453 & 384 & 469 & 785 \\
\hline ethanol & $<3$ & 4 & 3 & 3 & 5 \\
\hline n-propanol & $<3$ & 3 & 3 & $<3$ & 3 \\
\hline i-butanol & 13 & 6 & 8 & 7 & 6 \\
\hline \multirow[t]{2}{*}{ 2-methylbutanol-1 } & $<3$ & $<3$ & $<3$ & $<3$ & $<3$ \\
\hline & \multicolumn{5}{|c|}{$623^{\circ} \mathrm{K}$} \\
\hline Promoter $\mathbf{M}^{\mathbf{a}}$ & Pd I-st & Pd I & Pd II & Ru I & Ru II \\
\hline \multicolumn{6}{|l|}{$\begin{array}{l}\text { Liquid product } \\
\text { distribution }\end{array}$} \\
\hline$\%$ methanol & 84 & 90 & 94 & 90 & 87 \\
\hline$\%$ ethanol & 1 & 1 & 1 & 1 & 1 \\
\hline$\%$ n-propanol & $<1$ & 1 & $<1$ & $<1$ & 1 \\
\hline$\%$ i-butanol & 1 & 1 & 1 & 1 & 1 \\
\hline$\%$ 2-methylbutanol-1 & $<1$ & $<1$ & $<1$ & $<1$ & $<1$ \\
\hline \multicolumn{6}{|l|}{ STY $\left[\mathrm{g} /\left(\mathbf{l}_{\text {cat }} \cdot \mathbf{h}\right)\right]$} \\
\hline methane & 13 & $<10$ & 14 & $<10$ & $<10$ \\
\hline methanol & 517 & 504 & 739 & 477 & 441 \\
\hline ethanol & 4 & 4 & 5 & 3 & 5 \\
\hline n-propanol & 3 & 3 & 3 & $<3$ & 3 \\
\hline i-butanol & 8 & 8 & 7 & 4 & 5 \\
\hline 2-methylbutanol-1 & $<3$ & $<3$ & $<3$ & $<3$ & $<3$ \\
\hline
\end{tabular}

${ }^{a}$ Promoter M I: $0.024 \mathrm{mmol} \mathrm{M} / \mathrm{g}_{\text {cat }}$, M II: $0.10 \mathrm{mmol} \mathrm{M} / \mathrm{g}_{\text {cat }}$. 
Table 3.3.3

Product Distribution and STY Over Different $\mathrm{ZrO}_{2} / \mathrm{ZnO} / \mathrm{MnO} / \mathrm{K}_{2} \mathrm{O}-$ Catalysts; Unit II, $\mathrm{p}=12.5 \mathrm{MPa}, \mathrm{GHSV}=11,600 \mathrm{hr}^{-1}, \mathrm{~V}_{\text {cat }}=3.0 \mathrm{ml}, \mathrm{D}_{\text {cat }}=0.25-0.50 \mathrm{~mm}$, Syngas 1:1 $658^{\circ} \mathrm{K}$

\begin{tabular}{|c|c|c|c|c|c|}
\hline Promoter $\mathbf{M}^{\mathrm{a}}$ & - & $\mathbf{R h} \mathbf{I}$ & Rh II & Pt I & Pt II \\
\hline \multicolumn{6}{|l|}{$\begin{array}{l}\text { Liquid product } \\
\text { distribution }\end{array}$} \\
\hline$\%$ methanol & 71 & 80 & 76 & 74 & 76 \\
\hline$\%$ ethanol & $<1$ & 1 & 1 & 1 & 1 \\
\hline$\%$ n-propanol & $<1$ & $<1$ & 1 & 1 & 1 \\
\hline$\%$ i-butanol & 8 & 5 & 7 & 6 & 5 \\
\hline$\%$ 2-methylbutanol-1 & 1 & 1 & 1 & 1 & $<1$ \\
\hline \multicolumn{6}{|l|}{ STY $\left[g /\left(\mathbf{l}_{\text {cat }} \cdot h\right)\right]$} \\
\hline methane & 31 & 28 & 29 & 46 & 52 \\
\hline methanol & 365 & 435 & 406 & 416 & 526 \\
\hline ethanol & $<3$ & 4 & 4 & 6 & 8 \\
\hline n-propanol & $<3$ & $<3$ & $<3$ & 3 & 4 \\
\hline i-butanol & 42 & 28 & 37 & 33 & 36 \\
\hline \multirow[t]{2}{*}{ 2-methylbutanol-1 } & 4 & 3 & 3 & 3 & $<3$ \\
\hline & \multicolumn{5}{|c|}{$658^{\circ} \mathrm{K}$} \\
\hline Promoter $\mathbf{M}^{\mathrm{a}}$ & Pd I-st & Pd I & Pd II & Ru I & Ru II \\
\hline \multicolumn{6}{|l|}{$\begin{array}{l}\text { Liquid product } \\
\text { distribution }\end{array}$} \\
\hline$\%$ methanol & 74 & 69 & 73 & 76 & 71 \\
\hline$\%$ ethanol & 1 & 1 & 1 & 1 & 2 \\
\hline$\%$ n-propanol & 1 & 1 & 1 & 1 & 1 \\
\hline$\%$ i-butanol & 6 & 7 & 5 & 5 & 5 \\
\hline$\%$ 2-methylbutanol-1 & 1 & 1 & $<1$ & $<1$ & 1 \\
\hline \multicolumn{6}{|l|}{ STY $\left[g /\left(\mathbf{l}_{\text {cat }} \cdot h\right)\right]$} \\
\hline methane & 54 & 53 & 58 & 31 & 49 \\
\hline methanol & 466 & 437 & 552 & 516 & 449 \\
\hline ethanol & 8 & 7 & 11 & 7 & 11 \\
\hline n-propanol & 5 & 4 & 5 & 3 & 5 \\
\hline i-butanol & 40 & 42 & 37 & 31 & 31 \\
\hline 2-methylbutanol-1 & 5 & 4 & 4 & 3 & 4 \\
\hline
\end{tabular}

${ }^{\mathrm{a}}$ Promoter M I: $0.024 \mathrm{mmol} \mathrm{M} / \mathrm{g}_{\text {cat }}$, M II: $0.10 \mathrm{mmol} \mathrm{M} / \mathrm{g}_{\text {cat }}$. 